\section{Surgical Management of Multiple Myeloma and}

\section{Plasmocytoma of the Spine}

\author{
G Evangelisti1*, E Pesce1, R Gala², S Bandiera', G Tedesco', \\ G Barbanti Brodano' ${ }^{1}$ S Terzi' ${ }^{1}$ R Ghermandi', M Girolami' 1 V \\ Pipola ${ }^{1}$ and $A$ Gasbarrini ${ }^{1}$
}

${ }^{1}$ Oncologic and Degenerative Spine Surgery Unit, IRCCS Istituto Ortopedico Rizzoli, Bologna, Italy

${ }^{2}$ Department of Spine surgery, Hospital Kothari Medical Centre, Kolkata, West Bengal, India
Received: 26 March, 2020

Accepted: 08 September, 2020

Published: 10 September, 2020

*Corresponding author: G Evangelisti, Oncologic and Degenerative Spine Surgery Unit, IRCCS Istituto Ortopedico Rizzoli, Bologna, Italy,

E-mail: drevangelistigisberto@gmail.com

https://www.peertechz.com

Check for updates

\section{Introduction}

Multiple Myeloma (MM) is caused by the neoplastic proliferation of plasma cells that produce monoclonal immunoglobulins in the bone marrow thereby causing skeletal damage. Other MM-related complications include hypercalcemia, renal insufficiency, anaemia, and infections [1].

It represents $1 \%$ of all kinds of malignant neoplasms and more than $10 \%$ of the haematologic malignancies. The incidence of this pathology is about 4-5 patients per 100.000 persons [2].

Generally, it affects patients older than 40 years with a peak incidence ranging between 50 and 70 years [3], \&, with a predilection for males. Isolated lesions are found in $5-10 \%$ of cases [4,5], but with time the disease usually becomes systemic, with multiple lytic lesions [6,7]. About $85 \%$ of patients with multiple myeloma develop bone disease [8]. Due to the distribution of haematopoietic cells, the spine is one of the most frequent locations of the pathology [9]. The vertebral disease is a major cause of morbidity in $70 \%$ of patients diagnosed with multiple myeloma. Associated osteolytic lesions and vertebral fractures are well documented in causing debilitating pain, functional restrictions, spinal deformity, and cord compression [10]. Clinically a vertebral plasmocytoma shows up with symptomatology that varies from back pain, with or without minimal correlation with weight bearing [11], to acute back pain with structural instability due to pathological fracture to symptoms leading to neurological compression. The pathogenesis of the skeletal alteration develops through consecutive phases of bone marrow infiltrations, skeletal erosion caused by osteoclast activation and eventually resulting in the development of a neoplastic lesion. This osteoclast differentiation and activation is mediated by Receptor activator of nuclear factor-kappa B (RANK) and its ligand RANKL which are expressed strongly in the bone apart from other tissues like kidney, liver, thymus and lungs leading to osteolysis which is characterised by an imbalance within the bone remodelling processes with an increased reabsorption activity by osteoclasts and suppressed new bone formation. Other novel fact ors that directly stimulate osteoclastic bone destruction in myeloma are ostoepontin, macrophage inflammatory peptide $1 \alpha$, and interleukin (IL)3. All of these factors are increased in most patients with myeloma [12].Osteopontin too influences bone homeostasis by inhibiting mineral deposition, by promoting differentiation of osteoclasts and by enhancing osteoclast activity and it also increases the expression of $\mathrm{CD} 44$ on osteoclasts which is responsible for their enhanced motlity [13 ]. Bisphosphonates are specific inhibitors of osteoclastic activity. They are shown to be effective in reducing vertebral fractures and pain but their role is unclear in improving survival; zoledronate was found to be better than first-generation bisphosphonates (etidronate) in pooled direct and indirect analyses for improving outcomes as vertebral fractures [14].

The clinical variety and the burden of the pathology, with possible serious repercussions on the quality of life, impose a prompt diagnosis and an appropriate treatment planned in the context of a multidisciplinary general evaluation by a haematooncologist, a radiotherapist and the anaesthesiologist/ pain management specialist. 
MRI has a number of advantages over other imaging modalities and has become part of the routine assessment of patients with plasma cell disorders [15] and the gold standard for the study of this tumour in the spine.

Our objectives were to report on the efficacy of the surgical treatment in specific cases, in particular in patients with neurological complications as spinal cord compression, unmanageable pain, vertebral instability, in presence of pathologic fracture, or risk of it, and in cases resistant to chemotherapy and/or radiotherapy for which there is an indication to the surgical treatment [16]. The spinal cord compression affects two third of patients with solitary plasmacytoma with vertebral localisation, it is mainly due to fracture and vertebral collapse or more rarely to the direct compression of the neurological structures by the tumour itself [17]; this percentage lowers at $7-16 \%$ in cases of multiple myeloma [17].

Several comorbidities and laboratory measures predicted more rapid vertebral height loss and the development of future fracture, in particular, dyslipidemia, previous non-vertebral pathologic fracture related to MM, Durie-Salmon Stage III, osteopenia/osteoporosis, serum light chains, and serum calcium levels. Identifying risk factors for increased fracture burden may allow spine specialists to pursue earlier and appropriate interventions to optimise function and minimise morbidity [18].

In the case of neurological involvement the radiotherapy could control the tumor locally, but it is not sufficient to solve the concomitant instability for the treatment of which it is necessary a surgical stabilisation [3,9]. The maintenance of bone health in patients with multiple myeloma can significantly improve the quality of life [19]. The clinical consequences of bone lesions can be devastating for patients, negatively affecting the immediate and ongoing quality of life and worsening survival prospects [20].

\section{Material and methods}

This is a retrospective study where 124 patients from January 1st, 2000 to May 31st, 2015, affected by multiple myeloma with vertebral localisation were included. All the patients were operated at a single centre by senior surgeons belonging to a single unit. Demographic details like age, sex were noted. All patients, before the surgery, were studied with standard X-ray, bone scan, CT and MRI (Figures 1,2) of the spine and location, number, type of lesions were noted. Laboratory tests including serum immunoelectrophoresis and the BenceJones protein urine/blood test were also done. They were clinically assessed prior to surgery and patients were divided into those presenting with only pain, radicular symptoms and neurological deficit. Visual Analogue Scale (VAS) was used and the scores were categorised into mild, moderate and severe. Written and informed consents were taken regarding the surgical procedure they underwent. Intra and post operative complications, if any, were noted.

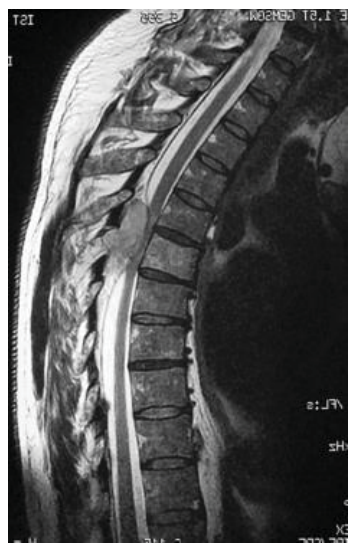

Figure 1: MRI T2 sagittal image.

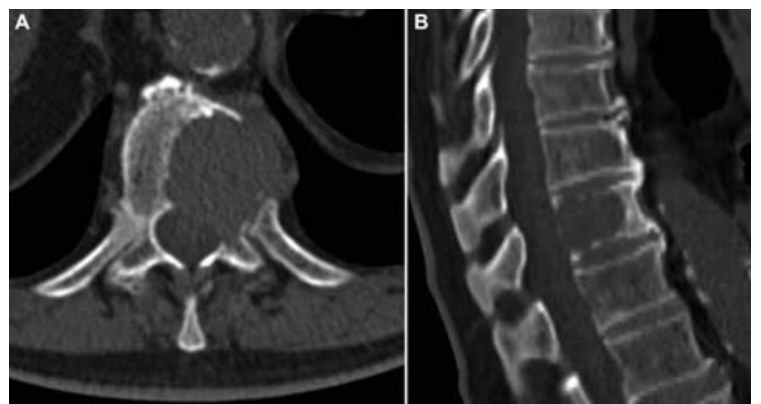

Figure 2: Axial and Sagittal CT Scans showing a lytic lesion in the thoracic spine with cortical breach.

\section{Results}

The Study comprised of 85 males 39 females aged between 31 and 85 years (mean 60 year. Four patients presented at our emergency department with a solitary lytic lesion, without peripheral deficits whose pain was manageable, only to undergo CT-guided needle biopsy for histological diagnosis and they had been managed conservatively. In 78 of 124 patients vertebral lesion was the only manifestation of the disease at the moment of admission, while 46 patients had other systemic manifestations along with multiple skeletal involvement. A total of 295 vertebras were involved. 39 cervical, 167 thoracic and 89 lumbar. Pain was the constant symptom with a mean of the Visual Analog Scale (VAS) score of 7.8. Pain was tolerable in 33 cases (VAS $<5$ ), moderate in 56 cases (VAS 5-7) and severe, resistant to major analgesics, in 35 patients (VAS> 7). Worsening spine cord compression signs were present in 29 cases. In 78 patients the pain was concomitant to a pathologic fracture (PF), associated or not to neurological symptoms. 30 patients $(23 \%)$ presented with neurological deterioration, 78 patients had $(63 \%)$ by the presented with a pathological fracture, 13 patients $(10.5 \%)$ had persistent pain despite chemotherapy, 5 cases $(4 \%)$ were resistant to chemotherapy and radiotherapy and the remaining 12 cases $(9.6 \%)$ were at the risk of impending pathological fracture. These 120 cases were subjected to 138 surgical interventions. A posterior approach was used in 126 interventions, anterior approach in 9, thoracotomy in 1 intervention \& lumbotomy in 2 interventions. The surgical interventions performed were wide laminectomy with posterior instrumentation, extracapsular 
intralesional excision, vertebroplasty and also vertebrectomy. The reconstruction of the vertebral body has been performed in 60 cases (Table 1 ) in the $16.7 \%$ of cases (10 patients) with a titanium cylinder filled with autograft, in the $72 \%$ of cases (43 cases) with acrylic cement, in the $3.6 \%$ (2 patients) with a carbon prosthesis filled with autograft , in the remaining $7 \%$ of cases ( 5 patients) with autologous bone.

All patients were constantly followed up during a mean period of 32.5 months (minimum 1 - maximum 151 months). The mean survival rate at 2 and 5 years, calculated according to the Kaplan-Meier method, were respectively $90 \%$ and $79 \%$. An important and significative reduction in postoperative pain ( mean VAS $=1.8$ ) was obtained in all patients.

We observed 20 complications $(14.5 \%)$ on a total of 138 surgical interventions (Tables 1 \&2).

Table 1: Method of Anterior Reconstruction.

\begin{tabular}{|c|c|}
\hline Cement & 43 \\
\hline Titanium Prothesis & 10 \\
\hline Carbon Prosthesis & 2 \\
\hline Autologous Bone Graft & 5 \\
\hline
\end{tabular}

Table 2: Types of Complications.

\begin{tabular}{|c|c|c|}
\hline $\begin{array}{c}\text { Type of } \\
\text { Complications }\end{array}$ & Details of Complications & $\begin{array}{c}\text { Total Number of } \\
\text { patients }\end{array}$ \\
\hline $\begin{array}{l}\text { Hematoma- } \\
\text { associated }\end{array}$ & $\begin{array}{c}\text { Cauda equina }(n=1 \\
\text { Lower limb weakness }(n=2) \\
\text { Sudden paraplegia }(n=1)\end{array}$ & 4 \\
\hline Wound related & $\begin{array}{l}\text { Wound hematoma }(n=1) \\
\text { Wound dehiscence }(n=2)\end{array}$ & 3 \\
\hline Surgery Related & $\begin{array}{c}\text { Hardware loosening with } \\
\text { hyperkyphosis }(n=3) \\
\text { Rod rupture }(n=1) \\
\text { Screws pulled out }(n=1) \\
\text { Left cervical loosening }(n=1) \\
\text { Mal positioning of } C 1 \text { screws }(n=1) \\
\text { Pathological fracture below } \\
\text { instrumentation }(n=1) \\
\text { Dysphonia }\end{array}$ & $8 \mathrm{~A}$ \\
\hline Medical & $\begin{array}{c}\text { Deep venous thrombosis } \\
\text { Acute kidney and respiratory failure } \\
\text { Pulmonary embolism } \\
\text { Intraoperative hyperthermia }\end{array}$ & 4 \\
\hline
\end{tabular}

- Complications were broadly classified into 4 main categories

- Haematoma associated

- Wound related

- Surgery related

- Medical

- Major neurological complications (classified as IIB according to the Calvier-Dindo classification adapted to spine surgery by Landrienl Ibanez [21,22]) due to compression of the neurological structures by

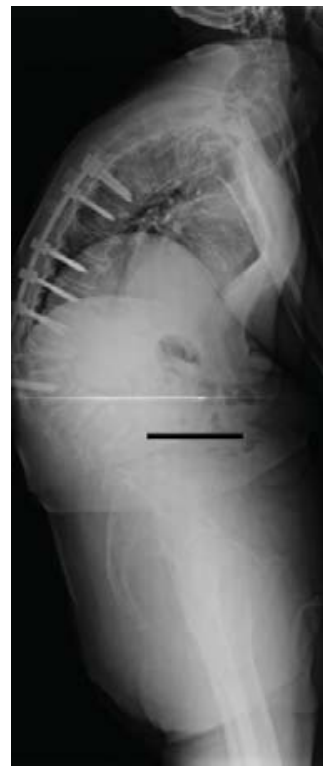

Figure 3: rx sagittal post

a haematoma underwent to surgical revision with evacuation of the haematoma. All 4 patients improved in function at 1 year follow up.

- 3 patients experienced problems with the wound closure and two cases underwent a surgical revision of the wound to allow the proper closure;

- 4 postoperative major medical complications occurred (Grade II $[21,22]$ ): one pulmonary embolism, one deep venous thrombosis, one case of acute renal failure associated with respiratory failure whereas one patient had intra operative hyperthermia.

- The majority of complications seen within our series are classifiable as surgery related or iatrogenic ( 9 in total) Figure 3.

Particularly interesting and surgically challenging was a case of G.E., male, 64 years old. In 2012 this patient underwent a stabilisation of the levels included from $\mathrm{T} 7$ to $\mathrm{L}_{3}$ and decompression at T8-T9 and L1-L2 for cauda equina syndrome following a pathologic fracture with cord compression. In 2014 he presented to our outpatient clinic for regular follow up with hyperkyphosis secondary to new pathologic fracture of L3, which was the level lower to the most caudal vertebra previously instrumented, associated with additional new pathologic fracture of $\mathrm{T} 6, \mathrm{~T} 9$, hardware mobilisation, and skin decubitus ulcer. He, therefore, underwent a new surgical intervention for hardware removal, vertebroplasty at T6, T9 and L3 and consecutive L1 corpectomy, deformity correction and reconstruction of the L1 vertebral body with autologous bone graft and lateral plate T12-L2. After 12 months from the second surgery hyperkyphosis and skin ulcers in the site of hardware, decubitus were still present. We met 2 minor complications (Grade I $[20,21]$ ) not directly correlated to the surgical intervention: a transient dysphonia and a case of intraoperative hyperthermia. 


\section{Discussion}

Multiple myeloma is a pathology of oncologic and haematologic pertinence. The spine surgeon gains a fundamental role in cases of vertebral localisation partially or not-at-all responsive to medical and radiotherapeutic treatments in which there is a progression or relapse of the disease [23]. Furthermore, the augmented efficacy of the medical treatments led to a higher life expectancy with the consequent and uncontested utility of the spine surgeon, above all with regard to the functional status [24].

Our series demonstrates effectively that in the majority of cases the surgeon performs surgical interventions aimed at the decompression of neurological structures, pain control, restoration of the stability and to correct frontal and sagittal alignment of the spine. Less frequently the prerequisites for the execution of an excision surgery exist; this kind of surgery must be reserved for the cases not sensitive to chemoradiotherapeutic protocols. The goal of excision is to remove in part or completely the neoplastic tissue surrounded by healthy tissue; the surgical approach could be posterior [25-27] and should be evaluated case by case in relation to the result desired and to the prognosis of the patient. In the majority of cases - from an oncologic point of view - it consists in intralesional interventions, extracapsular curettage [28] and only in a minority of cases the surgical indication to en-bloc resection [25], more useful and indicated in the local control of primitive tumours and some solitary metastasis resistant to radiotherapy and medical treatments. Also under this aspect, our series is compliant to the literature. In cases in which the goal of the surgery was the decompression of the neurological structures, a laminectomy without instrumentation has never been performed. A simple laminectomy allows a fair decompression but simultaneously has a high risk of instability and iatrogenic deformity with consequent possible neurological damage. Furthermore, a non-instrumented laminectomy, in the treatment of the neurological damage, presents an efficacy similar to radiotherapy, but with a higher risk of mechanical, neurological and systemic complications [29].

For these reasons, we have always opted in favour of a wide laminectomy, extended to the pedicles and sometimes to the posterior wall, necessarily followed by an instrumented arthrodesis effective in the respect of the three-dimensional balance of the spine. To obtain a circumferential decompression of the neurological structures it could be necessary to remove also part of the vertebral body near to the dural sac $[30,31]$, in association with a posterior arthrodesis, a reinforcement of the vertebral body for example with acrylic cement. The reconstruction of the vertebral body is mandatory in those cases in which, due to the extension of the disease, the loss of bone consequent to the removal of the tumour is so extended to create a remarkable mechanical instability; in these cases, therefore, all the mechanical solicitations would load on the posterior instrumentation with a consequent functional overload that with time could compromise the stability and the resistance of the implant [25]. For this purpose, the reconstruction of the removed vertebral body could be performed using autograft (iliac crest, fibula, rib) or homoplastic grafting through the use of titanium cylinder, cement (polymethyl methacrylate) or carbon prosthesis.

Through a posterior approach, at the thoracolumbar level, it is possible to essentially remove the entire vertebral body in an intralesional excision through the pedicles which could be performed also through an anterior approach (the only approach that allows a cervical corpectomy).

The combined anterior-posterior approach allows to remove of the entire vertebra or, through particular techniques, to remove en-bloc part or the entire vertebra with wide margins $[24,25,30]$ but it enhances the morbidity of the surgery.

Within our series, almost one-fourth of patients (23\%) underwent a surgical procedure for a worsening of the neurological conditions, with an improvement of the clinical status in the majority of cases. In $72 \%$ of cases, the surgical indication was dictated by the presence, or the impending risk, of a pathologic fracture in absence of neurological deficits.

In the majority of patients, an intralesional excision of the neoplastic mass with a reconstruction of the vertebral body has been performed ( $58 \%$ of cases). In 14 cases through an anterior approach, in 55 cases through a posterior approach and in 1 case through a combined anterior-posterior approach. In the $40 \%$ of cases, we opted instead for posterior instrumentation alone. Also, this kind of therapeutic approach, followed by radiotherapy, permitted a good local control of the disease; the percentage of local relapse has been, indeed, $0.8 \%$.

According to our experience, the vertebroplasty procedure was reserved for those cases in which after adequate medical and radiotherapeutic treatment the CT and MRI documented the absence of neoplastic mass with residual cavity with high risk, or presence, of fracture [32]. This surgical technique prevents a fracture, in case of high-risk vertebral body collapse, or in the case of pathologic fracture it reduces substantially the pain consequent to the mechanical instability of the spine. In five patients a new concept cement has been used; it is a silicone based cement, used in the attempt to reduce adjacent segment fractures which may occur in patients treated with PMMA; indeed the traditional cement is a very stiff material that could create excessive stress on the vertebras adjacent to the level treated [33-35].

In the perspective of multidisciplinary management of the oncologic patient, the radiotherapist should, therefore, consult a spine surgeon with experience in the oncologic field before proceeding with radiation treatment. In order to avoid local complications during and following a surgical procedure, as for example delayed wound closure or postoperative infections, the radiotherapy should not precede the surgery [36].

\section{Conclusions}

The role of the spine surgeon in the treatment of the multiple myeloma is principally a functional one.

The aim of the surgical intervention is to guarantee 
sufficient stability of the vertebral column and to decompress or preserve the integrity of the neurological structures. The prognosis of the single patient should always be considered in the choice of surgical intervention to perform. With this perspective the surgical options that we consider as more effective and appropriate are the following:

- Wide laminectomy and posterior instrumentation to solve or preserve the integrity of the neurological structures and, at the same time, to obtain sufficient mechanical stability of the spine;

- Extracapsular intralesional excision (debulking) in cases resistant to chemotherapy and radiotherapy that must be planned with the oncologist/haematologist (a multidisciplinary approach is required);

- Reconstruction of the vertebral body add to posterior instrumentation, in relation to the biomechanical needs of the spine;

- Vertebroplasty or kyphoplasty: to be reserved in those cases in which, after a pharmacological and/or radiotherapeutic treatment, remains a cavity in the vertebral body with a consequent high risk of fracture.

It is very important for us to emphasise that the patient affected by a multiple myeloma with vertebral localisation of the disease must be cared by an oncologic team which comprises the oncologist/haematologist, the radiotherapist, the spine surgeon, and the anaesthesiologist/pain management specialist; only through a multidisciplinary contest it is possible to improve not only life expectancy but also life quality.

\section{References}

1. Kumar SK, Callander NS, Alsina M, Atanackovic D, Biermann JS, et al. (2017) Multiple Myeloma, Version 3.2017, NCCN Clinical Practice Guidelines in Oncology. J Natl Compr Canc Netw 15: 230-269. Link: https://bit.ly/3meWFNO

2. Kyle RA, Rajkumar SV (2009) Treatment of multiple myeloma: a comprehensive review. Clin Lymphoma Myeloma 9: 278-288. Link: https://bit.ly/33cz9Y7

3. Durr HR, Kuhne JH, Hagena FW, Moser T, Refior HJ (1997) Surgical treatment for myeloma of the bone. A retrospective analysis of 22 cases. Arch Orthop Trauma Surg 116: 463-469. Link: https://bit.ly/33a0x7n

4. Bataille R, Sany J (1981) Solitary myeloma: clinical and prognostic features of a review of 114 cases. Cancer 48: 45-51. Link: https://bit.ly/336uGpW

5. Chak LY, Cox RS, Bostwick DG, Hoppe RT (1987) Solitary plasmacytoma of bone: treatment, progression and survival. J Clin Onco 5: 1811-1815. Link: https://bit.ly/2GKrsRt

6. Harrington KD (1988) Orthopaedic managment of metastatic bone disease. St Louis: CV Mosby Co 6: 116-117.

7. Oken MM (1984) Multiple myeloma. Med Clin North Am 68: 757-787. Link: https://bit.ly/2GKg1cw

8. Rome S, Noonan K, Bertolotti P, Tariman JD, Miceli T (2017) Bone Health, Pain, and Mobility: Evidence-Based Recommendations for Patients With Multiple Myeloma. Clin J Oncol Nurs 21: 47-59. Link: https://bit.ly/3ieNBVM

9. Durr HR, Wegener B, Krodel A, Muller PE, Jansson V, et al. (2002) Multiple myeloma: surgery of the spine: retrospective analysis of 27 patients. Spine 27 320-324. Link: https://bit.ly/2RaKvGE
10. Patel MS, Ghasem A, Greif DN, Huntley SR, Conway SA, et al. (2018) Evaluating Treatment Strategies for Spinal Lesions in Multiple Myeloma: A Review of the Literature. Int J Spine Surg 12: 571-581. Link: https://bit.ly/2R5HjvX

11. Thorn K, Williams J (1999) Solitary osseus plasmacytoma as a cause of back pain in a young patient. Am J Emerg Med 17: 615-617. Link: https://bit.ly/2FfFVo7

12. Ring ES, Lawson MA, Snowden JA, Jolley I, Chantry AD, et al. (2018) New Agents in the Treatment of Myeloma Bone Disease. Calcif Tissue Int 102: 196 209. Link: https://bit.ly/3m31rwX

13. Standal T, Borset M, Sundan A (2004) Role of osteopontin in adhesion, migration, cell survival and bone remodeling. Exp Oncol. 26: 179-184. Link: https://bit.ly/3bRTp5v

14. Mhaskar R, Kumar A, Miladinovic B, Djulbegovic B (2017) Bisphosphonates in multiple myeloma: an updated network meta-analysis Cochrane Database Syst Rev 12: CD003188. Link: https://bit.ly/3hhhX8S

15. Lasocki A, Gaillard F, Harrison SJ (2017) Multiple myeloma of the spine. Neuroradiol J 30: 259-268. Link: https://bit.ly/3m5oaZe

16. McLain RF, Weinstein JN (1989) Solitary plasmacytomas of the spine: a review of 84 cases. J Spinal Disord 2: 69-74. Link: https://bit.ly/2F623RU

17. Delauche-Cavallier MC, Lardo JD, Wybier M, Bard M, Mazabraud A, et al (1988) Solitary plasmacytoma of the spine. Long-term clinical course. Cancer 61: 1707-1714. Link: https://bit.ly/3hcXI1।

18. Xiao R, Miller JA, Margetis K, Lubelski D, Lieberman IH, et al. (2016) Predicting the progression of vertebral fractures in patients with multiple myeloma. Spine J 16: 510-515. Link: https://bit.ly/35k4dYP

19. Miceli TS, Colson K, Faiman BM, Miller K, Tariman JD, et al. (2011) Maintaining Bone Health in Patients With Multiple Myeloma: Survivorship Care Plan of the International Myeloma Foundation Nurse Leadership Board. Clin J Oncol Nurs 15: 9-23. Link: https://bit.ly/3igZOt9

20. International Myeloma Working Group (2003) Criteria for the classification of monoclonal gammopathies, multiple myeloma and related disorders: a report of the International Myeloma Working Group. Br J Haematol 121: 749-757. Link: https://bit.ly/3hargHD

21. Dindo D, Demartines N, Clavien PA (2004) Classification of Surgical Complications A New Proposal With Evaluation in a Cohort of 6336 Patients and Results of a Survey. Annals of Surgery 240. Link: https://bit.ly/2RaS9AB

22. Ibañez FAL, Hem S, Ajler P, Vecchi E, Ciraolo C, et al. (2011) A New Classification of Complications in Neurosurgery. World Neurosurg 75: 709715. Link: https://bit.ly/3bDADyz

23. Boriani S, Gasbarrini A, Paderni S, Bandiera S, Cappuccio M (2004) Terapia chirurgica delle lesioni vertebrali nel mieloma. Haematologica 89: 21-23.

24. Boriani S, Weinstein JN, Biagini R (1997) Spine update. Primary bone tumors of the spine. terminology and surgical staging. Spine 22: 1036-1044. Link: Link: https://bit.ly/35wYOOf

25. Magerl F, Coscia MF (1988) Total posterior vertebrectomy of thethoracic and lumbar spine. Clin Orthop 232: 62-69. Link: https://bit.ly/3jZAylj

26. Di Fiore M, Lari S, Boriani S, Formaro G, Perin S, et al. (1998) Major vertebral surgery: intra- and post-operative anaesthesia-related problems. Chir Org Mov 83: $65-72$.

27. Faciszewski T, Winter RB, Lonstein JE, Denis F, Johnson L (1995) The surgical and medical perioperative complications of anterior spinal fusion surgery in the thoracic and lumbar spine in adults. A review of 1223 procedures. Spine 20: 1592-1599. Link: https://bit.ly/2GIZ9D0

28. Enneking WF, Spainer SS, Goodman MA (1980) A system for the surgical staging of muscoloskeletal sarcomas. Clin Orthop 153: 106-120. Link: 
https://bit.ly/32agvks

29. Young RF, Post EM, King GA (1980) Tratment of spinal epidural metastases. Randomized prospective comparison of laminectomy and radiotherapy. J Neurosurg 53: 741-748. Link: https://bit.ly/3m0oA3b
30. Sundaresan N, Steinberger AA, Moore F, et al. (1996) Indications and results of combined anterior-posterior approaches for spine tumor surgery. J Neurosurg 85: 438-446. Link: https://bit.ly/33f5cqv

31. Gasbarrini A, Cappuccio M, Mirabile L, Bandiera S, Terzi S, et al. (2004) Spinal
Discover a bigger Impact and Visibility of your article publication with

Peertechz Publications

\section{Highlights}

* Signatory publisher of ORCID

* Signatory Publisher of DORA (San Francisco Declaration on Research Assessment)

* Articles archived in worlds' renowned service providers such as Portico, CNKI, AGRIS, TDNet, Base (Bielefeld University Library), CrossRef, Scilit, J-Gate etc.

- Journals indexed in ICMJE, SHERPA/ROMEO, Google Scholar etc.

* OAI-PMH (Open Archives Initiative Protocol for Metadata Harvesting)

* Dedicated Editorial Board for every journa

* Accurate and rapid peer-review process

* Increased citations of published articles through promotions

- Reduced timeline for article publication

Submit your articles and experience a new surge in publication services (https://www.peertechz.com/submission).

Peertechz journals wishes everlasting success in your every endeavours.

Copyright: @ 2020 Evangelisti G, et al. This is an open-access article distributed under the terms of the Creative Commons Attribution License, which permits unrestricted use, distribution, and reproduction in any medium, provided the original author and source are credited. 